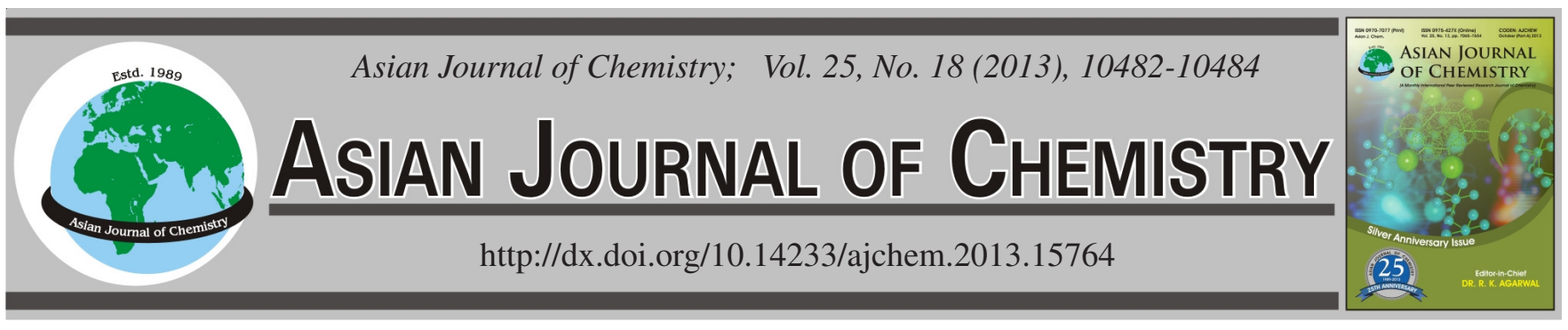

\title{
Evaluation of Chemical Characteristics of Swimming Pool Water and Poly(dimethyldiallylammonium chloride) Coagulation with Inactive Cryptosporidium parvum Oocysts in Pool Water
}

\author{
Tao Yuan, Ping Lu*, Qiyan Feng, Ting Li and Yue Sun
}

Department of Environmental Science and Spatial Informatics, China University of Mining and Technology, Xuzhou 221116, P.R. China

*Corresponding author: Tel: +86 51683591303; E-mail: lupingcumt@126.com

\begin{abstract}
Cryptosporidiosis has threatened public health significantly in swimming pool. Swimming pool water samples were collected and analyzed for chemical constituents from 40 swimming pools geographically distributed in one city in China, during one swimming season. Results showed investigated swimming pool water $\mathrm{pH}$ and free chlorine was in the recommended range, while hardness and alkalinity was higher. Three representative pool water was generated based on statistical analysis. Oxidation reduction potential (ORP) in the range of 800 to 880 for pools implied the investigated swimming pool water quality was acceptable. Zeta potential titration results show an upward trend of zeta potential with increased poly(dimethyldiallylammonium chloride) (pDADMAC) concentration, which indicated poly(dimethyldiallylammonium chloride) was a promising pool water treatment coagulant to help control cryptosporidiosis in pools. Additionally, poly(dimethyldiallylammonium chloride) could perform well in the three representative types of pool water with different chemical characteristics.
\end{abstract}

Key Words: Swimming pool, Cryptosporidiosis, Water chemical charateristic, Zeta potential.

\section{INTRODUCTION}

Public swimming pools pose significant health problem every year ${ }^{1}$. Possible pool water contaminants include disinfection by-products, urine, sweat, dirt, cosmetics, bacteria, algae, Cryptosporidium, Giardia and viruses. Therefore, swimming pool water quality investigation is critical in the concern of public health.

Swimming pool water $\mathrm{pH}$ should be monitored. The desired $\mathrm{pH}$ for disinfection and bather comfort should be maintained between 7.2 and 7.8 for chlorine disinfectants and between 7.2 and 8.0 for bromine-based and other non-chlorine disinfectants ${ }^{2-4}$. Chlorine is one of the most commonly used disinfectants for water disinfection ${ }^{1}$. The efficacy of disinfection is determined by the $\mathrm{pH}$. Disinfection will take place optimally when the $\mathrm{pH}$ is between 5 and 7 as then a maximum proportion of $\mathrm{HOCl}$ is present ${ }^{5}$. Chlorine is commercially available as gaseous chlorine $\left(\mathrm{Cl}_{2}\right)$ and as sodium hypochlorite liquid $(\mathrm{NaOCl})$ or calcium hypochlorite $\left[\mathrm{Ca}(\mathrm{OCl})_{2}\right]$. Hypochlorous acid $(\mathrm{HOCl})$ and hypochlorite ion $\left(\mathrm{OCl}^{-}\right)$are the products of $\mathrm{NaOCl}$ dissociation in water and are the two forms of free chlorine ${ }^{2-4}$.

Alkalinity and hardness is operational parameter. Alkalinity shows the acid neutralization capacity of the pool water and hardness shows the quantity of divalent cations such as calcium, magnesium and/or iron in water ${ }^{5}$. In general, pool water alkalinity should be kept between $80 \mathrm{mg} / \mathrm{L}$ and $125 \mathrm{mg} /$ $\mathrm{L}^{2-4}$. Calcium hardness and magnesium hardness are the primary ions contributing to water hardness with calcium typically accounting for $97 \%$ of the hardness ${ }^{2,3}$. Generally, calcium hardness levels are kept at 200 to $400 \mathrm{mg} / \mathrm{L}^{2,3}$. Pool water $\mathrm{pH}$, alkalinity and calcium hardness should be balance, for low alkalinity and hardness, the corrosiveness and aggressiveness of the pool water will be greatly increased and for high hardness and alkalinity, the scaling of water would occur.

Oxidation reduction potential (ORP) control of sanitizers in pools and spas is used all over the world. Oxidation reduction potential is used in pool water treatment as an indication of sanitation in relation to free chlorine parameter ${ }^{6}$. As shown in Fig. 1, the most important factor affecting sanitizer activity is $\mathrm{pH}$, because it changes the concentration of the more active form of free chlorine $(\mathrm{HOCl})$. As a result, chlorine becomes less effective at higher $\mathrm{pH}$. The recommended ORP level for pools and spas is typically between 650 and $750 \mathrm{mV}^{6,7}$, but it can be even higher in very clean water.

The idea of measuring the charges on particles goes to the heart of coagulation theory because it provides a rationale for determining coagulant dose. The behavior of colloidal particles in water is strongly influenced by their electrostatic charge. There are three approaches to measure particle charges 


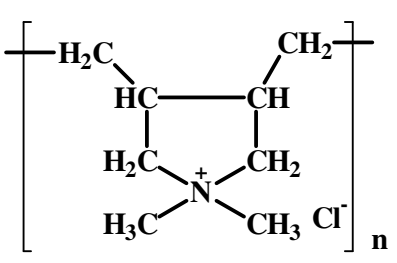

Fig. 1. Structure of poly(dimethyldiallylammonium chloride)

(i.e., zeta potential, colloid titration and streaming current $)^{8}$. Zeta potentials reported for Cryptosporidium parvum oocysts ranged approximately from $-40 \mathrm{mV}$ to $-10 \mathrm{mV}^{9-11}$.

According to zeta potential theory, particles with large negative or positive zeta potential are electrically stabilized (e.g., $>30 \mathrm{mV}$ or $<-30 \mathrm{mV})^{12}$. They will tend to repel each other and there is no tendency to flocculate. It had been shown conditions favorable for particle removal with zeta potential values ranging between $-10 \mathrm{mV}$ and $+10 \mathrm{mV}^{13,14}$. When the proper dosage of coagulant is added, zeta potential of particles should be approximate zero, theoretically. The point of zero charge (PZCs), represents the proper dosage of coagulant added. For a specific coagulant, the point of zero charge must be determined experimentally for a given water sample. The point of zero charge will be the first assessment of the potential to underdose and overdose each coagulant. However, zeta potential does not necessarily need to be zero for effective coagulation, since colloid destabilization occurs before complete neutralization of surface charge ${ }^{15}$.

The object of this paper is to investigate the swimming pool water chemical properties, such as $\mathrm{pH}$, total alkalinity as $\mathrm{CaCO}_{3}$, calcium hardness as $\mathrm{CaCO}_{3}$ in one typical large city in China. Samples were collected and analyzed for chemical constituents and water quality in order to assess the swimming pool water quality. In addition, zeta potential of Cryptosporidium parvum oocysts corresponding to different dosages of poly(dimethyldiallylammonium chloride) (pDADMAC) was investigated to gain insight into the dose-response relationship between pDADMAC and the surface charge of Cryptosporidium parvum oocysts suspended in the pool waters. It will be the first assessment of the potential to underdose and overdose for pDADMAC associated with particle coagulation using an electro-kinetic method.

\section{EXPERIMENTAL}

Poly(dimethyldiallylammonium chloride) production (1\%) chemical formula is shown in Fig. 1. Heat-inactivated C. parvum oocysts were used.

General procedure: Poly(dimethyldiallylammonium chloride) was titrated into different types of pool water with $10^{8}$ oocysts. The corresponding zeta potential was measured to set benchmarks for the pDADMAC. The benchmarks indicated the minimum, optimum maximum and flexibility of the dosage for each chemical in terms of zeta potential. Zeta potential variation during each test was measured. Before starting the titration, it was necessary to fill the titrant container with a specific concentration of the titrant and prime the titrant syringe pumps and tubes. An initial sample volume of $10 \mathrm{~mL}$ was used. Nitrogen was continuously added into the sample headspace to keep $\mathrm{CO}_{2}$ out of sample and control $\mathrm{pH}$. A measurement was not started until all the tubes were connected correctly and the capillary cell was filled.

Detection method: Forty swimming pool water samples were collected. Samples were collected in $500 \mathrm{~mL}$ high-density polyethylene (HDPE) plastic bottles and stored at $4{ }^{\circ} \mathrm{C}$. Duplicate samples were taken. Chemical constituents of each sample were analyzed using a Six-In-One Swimming Pool Test Kit (Product \# 1070, Shenzhen, China). The constituents measured were $\mathrm{pH}$, free chlorine, calcium hardness, total alkalinity, sulfate and CYA.

A zetasizer with an autotitrator (Malvern Instruments Ltd., Zetasizer Nano-ZS, Worcestershire, UK) was used as the zeta potential analyzer during the experiment. The disposable folded capillary cells were used. New tubing and circulation pump tubing were used for each experiment for quality control.

\section{RESULTS AND DISCUSSION}

Swimming pool water quality: Swimming pools were investigated with the mean pool volume of $10,000 \mathrm{~m}^{3}$. The maximum number of swimmers for one day was from 1,000 to 2,000 according to the survey questionnaire. Table- 1 shows the investigated pool parameters and recommended values by NSPF. Pool water $\mathrm{pH}$ was in the range of 7.2 to 8.4 , compared with the recommended range that between 7.2 to 7.8 and only one pool's pH was more than 7.8. High pH can lead to less effective disinfection, poor metal-based coagulation and pipe scale. Free chlorine was fall in the range of $1-5 \mathrm{mg} / \mathrm{L}$ for all pools. Oxidation reduction potential for the investigated pools was in the range of 800 to 880 based on $\mathrm{pH}$ and free chlorine values, which indicated the investigated swimming pool water quality was acceptable.

Sixty five percent of pools' hardness were above $300 \mathrm{mg} / \mathrm{L}$, among them, 10 pools hardness were more than $400 \mathrm{mg} / \mathrm{L}$. It recommends that calcium hardness should be maintained at 200-400 as $\mathrm{CaCO}_{3}$ to prevent corrosion or pipe scale accumulation $^{2}$. Majority $(80 \%)$ of pools' alkalinity were out of the upper limitation. Alkalinity greater than $200 \mathrm{mg} / \mathrm{L}$ was observed in five pools, which could lead to difficulty in adjusting ${ }^{2} \mathrm{pH}$.

A correlations matrix with all the pairwise correlations between the four operational parameters, $\mathrm{pH}$, hardness, alkalinity and free chlorine, were examined by REML method. From the correlation matrix, the hardness of samples was

TABLE - 1

CHEMICAL VALUES FOR THE SWIMMING POOLS

\begin{tabular}{|c|c|c|c|c|}
\hline & Minimum & Maximum & Mean & Recommended \\
\hline $\mathrm{pH}$ & 7.2 & 8.4 & 7.8 & $7.2-7.8$ \\
\hline Hardness (mg/L) & 150 & 470 & 302 & $200-400$ \\
\hline Alkalinity (mg/L) & 98 & 327 & 220 & $80-125$ \\
\hline Free Chlorine (mg/L) & 1.5 & 3.6 & 2.6 & $1-5$ \\
\hline Temperature $\left({ }^{\circ} \mathrm{C}\right)$ & 26 & 30 & 28 & N/A \\
\hline
\end{tabular}


negatively correlated with the other parameters, which indicated the high hardness generally existed in low $\mathrm{pH}$, alkalinity and free chlorine water. Swimming pool water sample $\mathrm{pH}$ was positively correlated with alkalinity and free chlorine. Other relationships between these variables were also evident as shown in Table-2. Based on the data, three representative pool water was generated and summarized in Table-3.

\begin{tabular}{|c|c|c|c|c|}
\hline \multicolumn{5}{|c|}{$\begin{array}{l}\text { TABLE-2 } \\
\text { PAIR-WISE CORRELATIONS FOR OPERATIONAL } \\
\text { PARAMETERS }\end{array}$} \\
\hline & Hardness & $\mathrm{pH}$ & Alkalinity & Free Chlorine \\
\hline Hardness & 1 & -0.5 & -0.05 & -0.33 \\
\hline $\mathrm{pH}$ & -0.5 & 1 & 0.33 & 0.25 \\
\hline Alkalinity & -0.05 & 0.33 & 1 & -0.3 \\
\hline Free Chlorine & -0.33 & 0.25 & -0.3 & 1 \\
\hline \multicolumn{5}{|c|}{$\begin{array}{c}\text { TABLE-3 } \\
\text { TABLE }\end{array}$} \\
\hline & & pe 1 & Type 2 & Type 3 \\
\hline $\mathrm{pH}$ & & 7.2 & 7.6 & 7.8 \\
\hline Hardness ( $\mathrm{mg} /$ & & 450 & 300 & 150 \\
\hline Alkalinity (mg) & & 300 & 200 & 100 \\
\hline Free Chlorine & /L) & 1 & 2 & 3 \\
\hline Temperature ${ }^{\circ}$ & & 28 & 29 & 29 \\
\hline
\end{tabular}

Poly(dimethyldiallylammonium chloride) coagulation evaluation: The zeta potential of simulated water types with $10^{8}$ oocycts $/ \mathrm{mL}$ versus coagulant concentration is plotted in Fig. 2. Titration experiments suggested zeta potential of suspension increased in the positive direction as coagulant dosage increased. Previous study of drinking water revealed that achieving a zeta potential between $-10 \mathrm{mV}$ and $10 \mathrm{mV}$ for the suspension being treated was the destabilized system ${ }^{14}$. Poly(dimethyldiallylammonium chloride) solution concentration between 0.5 to $3 \mathrm{mg} / \mathrm{L}$ resulted in zeta potentials of -10 to $10 \mathrm{mV}$. Results indicated the reversal of charge was present as the coagulant concentrations increased. Over dose of pDADMAC was indicated by zeta potential above $10 \mathrm{mV}$. Different water types referred to the different $\mathrm{pH}$, alkalinity, hardness and ion concentration. The similar trends of zeta potential in different water types were observed. It showed water chemical characteristic had rarely impact on pDADMAC performance. The possible reason was polymer tends to be less $\mathrm{pH}$ dependent $\mathrm{t}^{5,16-18}$.

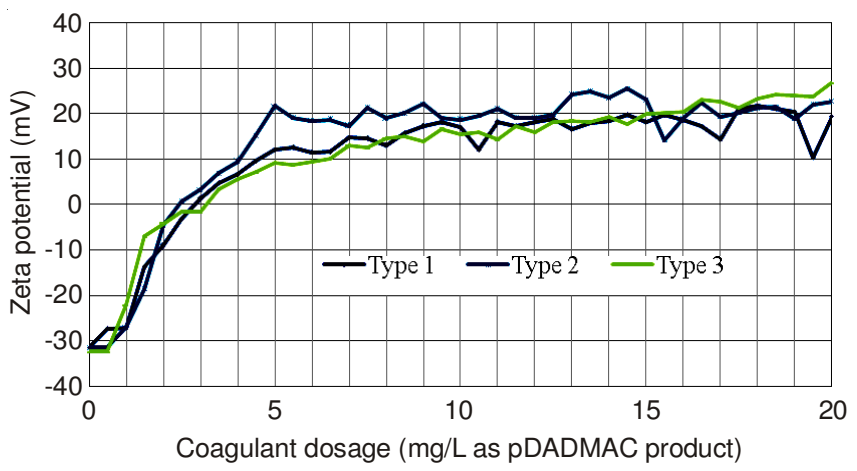

Fig. 2. Comparisons of zeta titration results for three types of swimming pool water

\section{Conclusion}

Relationships between $\mathrm{pH}$, free chlorine, hardness and alkalinity were evident. The hardness of samples was negatively correlated with the other parameters indicating the high hardness generally existed in low $\mathrm{pH}$, alkalinity and free chlorine water. Swimming pool water sample $\mathrm{pH}$ was positively correlated with alkalinity and free chlorine. It revealed the ORP for the investigated pools was in the range of 800 to 880 which indicated the investigated swimming pool water quality was acceptable.

Zeta potential titration results show an upward trend of zeta potential with increased coagulant dosage. Poly(dimethyldiallylammonium chloride) solution concentration between 0.5 $\mathrm{mg} / \mathrm{L}$ to $3 \mathrm{mg} / \mathrm{L}$ resulted in zeta potentials of -10 to $10 \mathrm{mV}$. Overdosing of pDADMAC was indicated by zeta potential above $10 \mathrm{mV}$. No significant differences were observed for coagulant performance on different water types. Therefore, pDADMAC was a potential effective coagulant for swimming pool water treatment to flocculate with C. parvum oocysts.

\section{ACKNOWLEDGEMENTS}

This project is supported by The Fundamental Research Funds for the Central Universities (2013QNB08).

\section{REFERENCES}

1. P. Lu, T. Yuan, Q. Feng, A. Xu and J. Li, Water Quality Res. J. Canada, 48, 30 (2013)

2. NSPF, NSPF Pool and Spa Operator Handbook (2009)

3. P.H. Perkins, Swimming Pools: Design and Construction, Spon Press, London, edn 4 (2000).

4. WHO, Guidelines for Safe Recreational-Water Environments, Swimming Pools, Spas and Similar Recreational-water Environments, Vol. 2 (2000).

5. D.W. Hendricks, Coagulation, in Water Treatment Unit Processes: Physical and Chemical, CRC Press, Taylor \& Francis Group, Boca Raton: FL (2006)

6. J.M. Steininger, PPM or ORP: which should be used? Santa Barbara Control Systems (1985).

7. J. Steininger, RP Control in Pools and Spas, Santa Barbara Control Systems (1998)

8. N. Hankins, N. Lu and N. Hilal, Sep. Purif. Technol., 51, 48 (2006).

9. C.F. Brush, Appl. Environ. Microbiol., 64, 4439 (1998).

10. C. Drozd and J. Schwartzbrod, Appl. Environ. Microbiol., 62, 1227 (1996).

11. K. Shaw, S. Walker and B. Koopman, J. Am. Water Work Assoc., 92, 103 (2000).

12. ASTM, Zeta Potential of Colloids in Water and Wastewater, in ASTM Standard D 4187-82. American Society for Testing and Materials, (1985).

13. K.McCurdy, K. Carlson and G. Gregory, Water Res., 38, 486 (2004).

14. T. Tseng, B.D. Segal and M. Edwards, J. Am. Water Work Assoc., 92, 44, (2000).

15. H. Ratnaweers, N. Hiller and U. Bunse, Environ. Int., 25, 347 (1999).

16. C. Huang, S. Chen and J.R. Pan, Water Res., 34, 1057 (2000).

17. C. Huang and C. Yin, J. Chem. Technol. Biotechnol., 66, 227 (1996).

18. T. Yuan, B. Han and P. Liu, J. Food Agric. Environ., 11, 1098 (2013) 